\title{
Interpretando a internacionalização dos periódicos científicos brasileiros
}

\author{
Lúcia da Silveira ${ }^{1}$ \\ Lara Benedet ${ }^{2}$ \\ Julio Santillán-Aldana ${ }^{3}$
}

\section{RESUMO}

Explora o processo de internacionalização acadêmica dos periódicos científicos brasileiros. Mediante revisão bibliográfica, é analisado o cenário do desenvolvimento dessas publicações nas últimas décadas na América Latina, assim como as recentes ações das agências nacionais de fomento à Ciência, Tecnologia e Inovação (CT\&l) para sua internacionalização. Conclui-se que, não existindo um plano para a internacionalização dos periódicos científicos brasileiros, é necessário o diálogo entre os diferentes atores para alcançar uma conjuntura inclusiva, em que prevaleça o princípio da informação científica como bem público e o livre acesso à produção científica a qualquer cidadão.

Palavras Chave: Internacionalização. Brasil. Periódicos científicos. Editoração. Avaliação acadêmica. Acesso aberto.

\section{Interpreting the internationalization of brazilian scientific journals}

It explores the process of academic internationalization of Brazilian scientific journals. Through a bibliographic review, it analyzes the scenario of the development of these

1 Mestre em Gestão da Informação (UDESC). Bibliotecária do Sistema de Bibliotecas da UFSC, coordenadora do Portal de Periódicos Científicos UFSC. Contato: luciadasilveiras@gmail.com

2 Graduanda em Design na UFSC. Atua com criação de identidades visuais para periódicos. Contato: larasbenedet@ gmail.com

3 Doutor em Ciência da Informação (UnB). Assessor, editor científico e avaliador de revistas de Ciência da Informação no Brasil, Chile e Peru. Editor regional do repositório Eprints Library and Information Science (E-LIS). Contato: julio.santillan@gmail.com

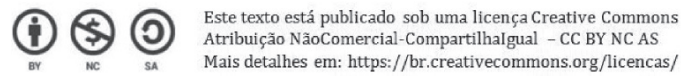


publications in the last decades in Latin America, as well as the recent actions of the national agencies for the promotion of science, technology and innovation (STI) for their internationalization. It is concluded that, in the absence of a plan for the internationalization of Brazilian scientific journals, dialogue between the different actors is necessary to achieve an inclusive situation, where the principle of scientific information as a public good prevails, together with free access to scientific production for any citizen.

Keywords: Internationalization. Brazil. Scientific journals. Publishing. Academic evaluation. Open Access.

Interpretando la internacionalización de las revistas científicas brasileñas

Explora el proceso de internacionalización académica de las revistas científicas brasileñas. Mediante la revisión bibliográfica es analizado el escenario del desarrollo de estas publicaciones en las últimas décadas en América Latina, así como las recientes acciones de las agencias nacionales de fomento a la Ciencia, Tecnología e Innovación (CT\&l) para su internacionalización. Se concluye que, no existiendo un plan para a internacionalización de las revistas científicas brasileñas, es necesario el diálogo entre los diferentes actores para alcanzar una coyuntura inclusiva, donde prevalezca el principio de la información científica como bien público y el libre acceso a la producción científica a cualquier ciudadano.

Palabras Clave: Internacionalización. Brasil. Revistas científicas. Edición. Evaluación académica. Acceso abierto.

\section{INTRODUÇÃO}

Na segunda década deste século, e como parte de seu processo de consolidação, as revistas científicas da América Latina têm conseguido incorporar no seu processo de desenvolvimento ações relacionadas ao acesso e à disseminação/distribuição e, consequentemente, à visibilidade dessas publicações no contexto da comunidade científica internacional. Prova disso é a sua incorporação em diversos tipos de bases de dados ou indexadores internacionais.

Além disso, dois aspectos importantes e estratégicos de fundo foram alcançados nesses processos: o reconhecimento da ciência e, portanto, da comunicação científica, como um bem comum, um bem público, e a necessidade de fomento constante do Acesso Aberto às informações científicas produzidas com fundos públicos. Isso foi conseguido integrando-se os esforços dos diversos atores, internos e externos, nacionais e regionais, que participam do processo de produção editorial e publicação desses periódicos.

Não obstante, nos últimos anos, as agências nacionais de fomento à Ciência, Tecnologia e Inovação (CT\&I) da região, a propósito de acrescentar o grau da internacionalização nos periódicos de seus países, propuseram políticas específicas para canalizar 
seu apoio a eles, focadas em um modelo que não considera necessariamente os aspectos estratégicos antes indicados. Isso é preocupante, considerando que muitos dos delineamentos dessas políticas desestimulam os esforços e as conquistas alcançadas pelos editores daquelas publicações.

Tendo em vista esse contexto, o presente artigo visa analisar alguns aspectos da internacionalização dos periódicos científicos brasileiros mediante a abordagem exploratória revisão bibliográfica e documental. Para isso, apresentamos uma breve contextualização do desenvolvimento dessas publicações na América Latina, revelando os problemas acarretados pelas recentes políticas de internacionalização, incluindo o próprio caso brasileiro.

\section{DESENVOLVIMENTO DOS PERIÓDICOS LATINO-AMERICANOS}

Numa análise retrospectiva dos principais acontecimentos no desenvolvimento de periódicos da região latino-americana nas últimas décadas, Alperin e Rozemblum (2017), distinguem três etapas a considerar: emergente, consolidação e internacionalização (Quadro 1).

Quadro 1 - Etapas do desenvolvimento dos periódicos científicos regionais

\begin{tabular}{|c|c|c|c|}
\hline Etapa & Denominação & Período & Tendência \\
\hline Primeira & Emergente & $1985-1995$ & $\begin{array}{c}\text { Normalização - Início da automatização do fluxo } \\
\text { editorial, instabilidade da interoperabilidade entre } \\
\text { sistemas. }\end{array}$ \\
\hline Segunda & $\begin{array}{c}\text { Consolidação } \\
\text { (regionalização) }\end{array}$ & $1995-2015$ & $\begin{array}{c}\text { Visibilidade e impacto - Maior apoio governamental } \\
\text { e profissionalização. }\end{array}$ \\
\hline Terceira & Internacionalização & $2015-H o j e$ & $\begin{array}{c}\text { Citação em base de dados comerciais; atendimento } \\
\text { a agendas temáticas internacionais X nacionais. } \\
\text { Ciência Aberta e cidadã. }\end{array}$ \\
\hline
\end{tabular}

Fonte: Elaborado pelos autores com base em: Alperin e Rozemblum (2017) Anglada e Abadal (2018), Uribe-Tirado e Ochoa (2018).

Para os autores, na etapa emergente, foram tornados públicos alguns problemas em relação aos periódicos latino-americanos, circunstância que fez com que essas publicações se adaptarem às exigências estabelecidas no contexto dos periódicos que pertencem à corrente da ciência central ${ }^{4}$. Complementarmente, foram criadas legislações e políticas para apoiar os periódicos nacionais, especialmente no seu processo de normalização editorial.

A segunda etapa, também chamada de idade de ouro, caracterizou-se pela estabilidade dos projetos editoriais, sua valorização, o apoio governamental para o desenvolvimento deles, e a motivação da comunidade científica, gerando crescimento e melhoria

4 Entende-se por ciência central a hegemonia temática estimulada por um grupo de pesquisadores dos países que dominam a ciência, por exemplo, os Estados Unidos e a Europa; no entanto, as agendas de interesses desses países são divergentes das dos países da América Latina, porque são realidades distintas, convergindo apenas em alguns casos. 
dos periódicos nos países da região (ALPERIN; ROZEMBLUM, 2017). Quanto aos aspectos formais do periódico, ficou evidente a necessidade de viabilizar a qualidade editorial para promoção da visibilidade, da distribuição, do alcance e do acesso (ALPERIN; ROZEMBLUM, 2017; CETTO, 2015; ALONSO GAMBOA, 2011). No fim dessa fase, a profissionalização dos editores foi mais exigida do que em relação aos outros anos.

Dentro desse período, algumas iniciativas de Acesso Aberto surgiram antes mesmo da consolidação desse movimento na América Latina, por exemplo: Índice Latino-Americano de Publicações Científicas Seriadas $\left(\right.$ Latindex $^{5}$ ), Scientific Electronic Library Online $\left(\mathrm{SciELO}^{6}\right)$ e Rede de Revistas Científicas da América Latina, Caribe, Espanha e Portugal (REDALYC ${ }^{7}$ ). Outros exemplos, ocorreram na década de 2000, com os portais de periódicos institucionais, ligados principalmente às universidades, que começaram a ganhar confiança. Estes receberam infraestrutura e passaram a oferecer serviços de modo a otimizar os recursos das instituições e a melhorar a qualidade dos periódicos, principalmente no que tange às características de forma, padronização, profissionalização de editores, indexação, análises estatísticas e divulgação científica. Os portais são normalmente vinculados a uma instituição de ensino superior e tem como função essencial democratizar a informação, por meio dos princípios do Acesso Aberto e da promoção das funções da comunicação científica, garantindo a preservação digital e a segurança de informação (SILVEIRA, 2016). São exemplos de Portais de Periódicos na América Latina: Portal de Revistas Acadêmicas da Costa Rica, Revistas da Universidade Nacional de Córdoba (Argentina), Portal de Revistas Acadêmicas da Universidade do Chile, Portal de Revistas da Universidade Católica do Uruguay, Portal de Revistas da Universidade de Lima (Peru); no Brasil, há muitas iniciativas de portais, destacando-se o Portal de Revistas USP, o Portal de Periódicos FIOCRUZ e o Portal de Periódicos UFSC.

No que se refere à terceira e última etapa, que trata da internacionalização, Alperin e Rozemblum (2017) mostram que há um movimento contraditório ao das etapas anteriores, o qual prejudica o fortalecimento dos periódicos latino-americanos que estão predominantemente em Acesso Aberto, justamente por serem implementadas políticas que visam à valorização do modelo de ciência desenvolvido nos países centrais (ALPERIN; ROZEMBLUM, 2017), não respeitando os esforços praticados pelas instituições. As instituições de fomento oferecem apoio estratégico, focalizado nas áreas escolhidas como prioritárias e de interesse das políticas nacionais em CT\&I, vinculam modelos coercitivos de políticas de internacionalização baseadas na inclusão dos periódicos nas cinco grandes

5 Criado em 1995, na Universidade Nacional Autônoma do México (UNAM), surgiu devido a um evento em 1994, em que editores sentiram falta de um sistema de informação próprio para representar os países da América Latina e Caribe.

6 Concebido em 1996, pela Fundação de Amparo à Pesquisa do Estado de São Paulo (FAPESP), pelo Centro LatinoAmericano e do Caribe de Informação em Ciências da Saúde (BIREME) e por editores de revistas científicas. Seu objetivo é "melhorar a qualidade e o impacto dos periódicos que indexa e das pesquisas que divulga". (PACKER, et al., 2014, p. 41).

7 Criado em 2003 "por grupo de pesquisadores e editores preocupados com a baixa visibilidade dos resultados de pesquisa gerados na e sobre a região." 
editoras comerciais reconhecidas mundialmente (Elsevier - Scopus, Clarivate - Thomsom Reuters - Web of Science, Wiley-Blackwell, Springer e Taylor \& Francis) (LARIVIÈRE; HAUSTEIN; MONGEON, 2015), sem considerar o modelo de publicação de Acesso Aberto desenvolvido nos próprios países.

Complementando o contexto da terceira etapa, percebe-se que haverá mudanças na comunicação científica relacionadas diretamente com a Ciência Aberta. A Ciência Aberta altera a cultura de trabalho dos pesquisadores, porque envolve muito mais que o acesso ou a consulta de informação, trazendo a criação de conteúdos educacionais abertos, códigos abertos, dados abertos para garantir a reprodutibilidade da pesquisa, a colaboração aberta e o feedback ou revisão aberta contínua da pesquisa, promovendo a participação ativa do cidadão (URIBE-TIRADO, OCHOA, 2018). Um dos princípios da Ciência Aberta é que a pesquisa deve ser feita com e para a sociedade (ANGLADA; ABADAL, 2018). Os conceitos, os princípios, as políticas e as novas estruturas tecnológicas da Ciência Aberta serão inevitáveis na concepção de um novo periódico, bem como na formulação de políticas públicas de investimento voltadas à pesquisa, para a construção de uma agenda temática local, nacional e internacional.

\section{A INTERNACIONALIZAÇÃO DOS PERIÓDICOS NA AMÉRICA LATINA}

O termo internacionalização não é uma expressão nova, mas tem sido usado com frequência nas últimas duas décadas para se referir aos diferentes aspectos que envolvem a educação internacional (KNIGHT, 2004, p. 9). Para a Red de Indicadores de Ciencia y Tecnología Iberoamericana e Interamericana (ALBORNOZ, 2009, p. 9), a internacionalização é uma característica da ciência e da tecnologia, resultado das expressões de dimensão internacional nos múltiplos atores, processos, resultados e impactos associados com a pesquisa científica e o desenvolvimento tecnológico. Em uma perspectiva mais abrangente, Knight (2004, p. 11, grifo nosso) define esse fenômeno como o "processo de integração de uma dimensão internacional, intercultural ou global aos propósitos, às funções e à provisão do ensino superior".

A internacionalização dos periódicos científicos proporciona visibilidade à produção científica e possibilita o aumento da colaboração internacional (PEREIRA; LOBAO; LUCAS, 2017, p. 2.300). Assim, essas publicações se vinculam ao processo de internacionalização nos segmentos de produção e colaboração científica. Por essa razão, a ausência das revistas científicas da região nas bases de dados dos sistemas de indexação é interpretada pelas agências governamentais como invisibilidade. Consequentemente, é tida como uma limitante para a mensuração da produção científica e, por conseguinte, do nível de desenvolvimento atingido pela ciência. Com essa finalidade, de mensurar para avaliar e sugerir políticas, as agências nacionais de apoio à pesquisa dos países da América Latina adotaram modelos propostos pelos organismos internacionais, como nota Quispe-Gerónimo (2015). 


\begin{abstract}
A partir da década dos noventas, o conceito para a avaliação da pesquisa orientouse para o uso de métricas baseadas no Web of Science (fator de impacto, índice de imediação) [...] contudo, o problema é que este tipo de avaliação está orientado especificamente aos dados e não ao julgamento da comunidade [...] O grande questionamento para os sistemas nacionais de avaliação é que todos usam conceitos baseados nas métricas científicas (QUISPE-GERÓNIMO, 2015, p. 1).
\end{abstract}

Paralelamente à indexação dessas publicações, e como parte do processo de internacionalização da ciência, as agências incentivaram os pesquisadores a publicar em periódicos da corrente principal, mesmo que isso fosse prejudicial para as revistas científicas locais que estão fora daquele perfil. A tendência de adotar esses sistemas de indexação como fontes de referência advém de seu prestígio e reconhecimento pela comunidade científica da corrente central ${ }^{8}$, além da circunstância de serem serviços proprietários. Os guias de maior prestígio para a internacionalização e avaliação da ciência, usados pelas agências governamentais, incluem seções relacionadas à produtividade baseada no número de artigos publicados, trabalhos em coautoria, índices de citação e outros dados bibliométricos (ESTADOS UNIDOS, 2016; ALBORNOZ, 2009; UNIÃO EUROPEIA, 2003), registrados, na maioria dos casos, nas bases de dados de indexação das grandes editoras internacionais comerciais. Nesse sentido, Vasen e Lujano Vilchis (2017, p. 203) consideram que "é um risco dar tanto valor nas avaliações às publicações dessas bases de dados, porque podem negligenciar os resultados de pesquisa" oriundos de países da América Latina.

Na América Latina, o processo de indexação nesses sistemas vem se intensificando desde a década de 1990. No quadro 2, resumimos os principais critérios de internacionalização das agências de fomento da Argentina, do México e da Colômbia vinculados àquelas bases de dados.

8 Corrente central é entendido como o domínio da ciência pelos países desenvolvidos e com maior investimento em CT\&I, também chamada de corrente principal. 
Quadro 2 - Critérios de internacionalização

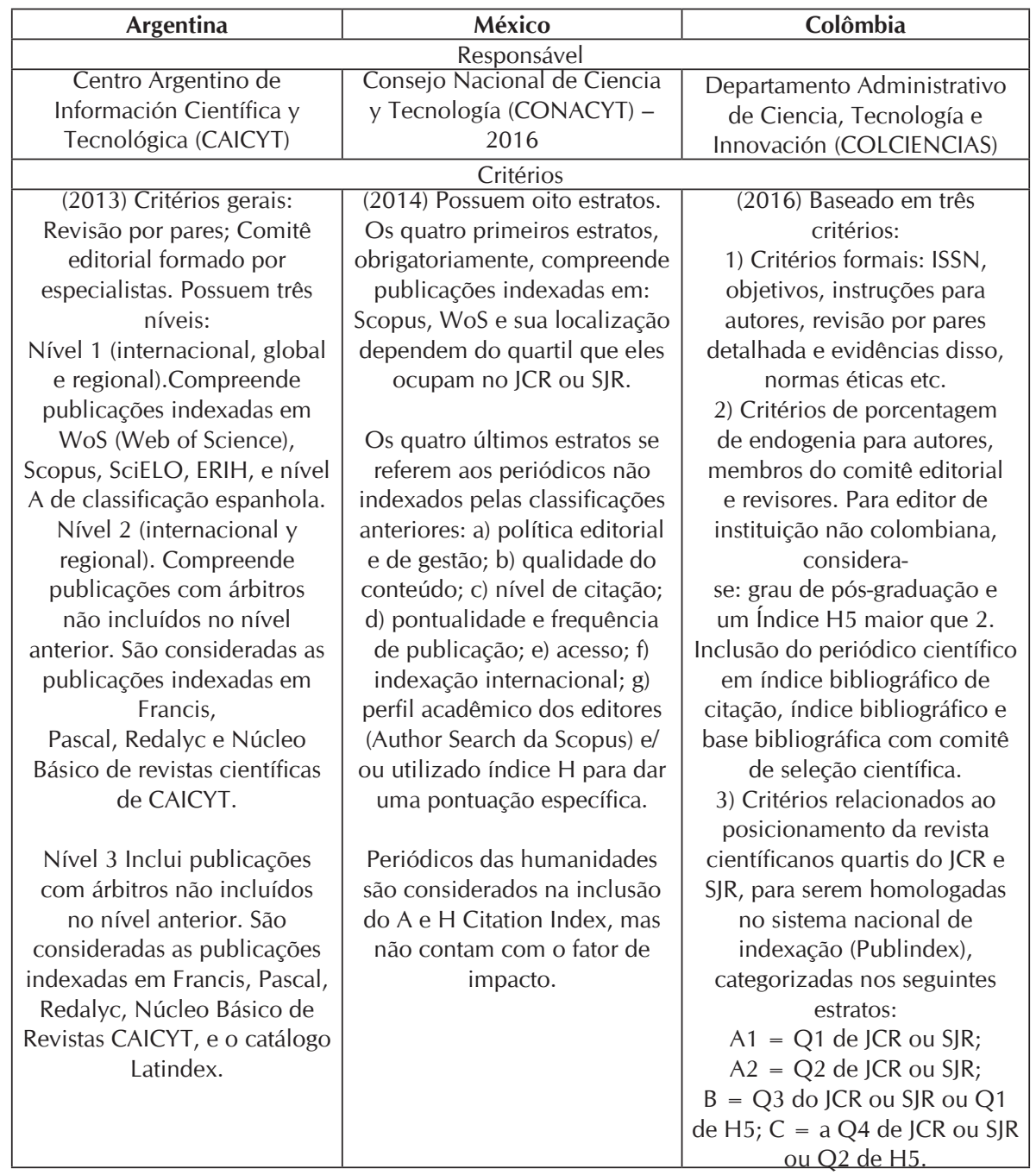




\begin{tabular}{|c|c|c|}
\hline Argentina & México & Colômbia \\
\hline \multicolumn{3}{|c|}{ Síntese da percepção dos autores } \\
\hline $\begin{array}{c}\text { É um avanço ter considerado } \\
\text { o SciELO no primeiro nível. } \\
\text { Porém, uma falha em não } \\
\text { ter considerado o Redalyc } \\
\text { em nível } 1 \text { e o Latindex no } \\
\text { nível } 3 . \\
\text { Não há referência sobre o } \\
\text { Acesso Aberto. }\end{array}$ & $\begin{array}{c}\text { Utiliza dois sistemas, um com } \\
\text { a base de dados bibliométrica, } \\
\text { e outro com estratificação } \\
\text { própria. } \\
\text { Reforça que a única forma de } \\
\text { consagração das publicações } \\
\text { é estar dentro desses índices } \\
\text { (Scopus e WoS). } \\
\text { Constitui-se em uma hierarquia } \\
\text { de periódicos. } \\
\text { Não há referência sobre o } \\
\text { Acesso Aberto nem considera } \\
\text { o SciELO ou Redalyc. }\end{array}$ & $\begin{array}{l}\text { 1) devido aos requisitos } \\
\text { mais rigorosos da política de } \\
\text { avaliação, alguns periódicos } \\
\text { científicos podem ser extintos } \\
\text { ou mesclados como o mesmo } \\
\text { modelo propõe (URIBE- } \\
\text { TIRADO, 2016); } \\
\text { 2) O mais provável é que } \\
\text { as revistas científicas sejam } \\
\text { rebaixadas e até mesmo a } \\
\text { A1, já que há poucas revistas } \\
\text { científicas no primeiro quartil } \\
\text { do JCR e SJR; 3) Existe o } \\
\text { risco de reduzir a recepção } \\
\text { de documentos, com a } \\
\text { consequente dificuldade } \\
\text { para manter a periodicidade } \\
\text { (AGUDELO TRUJILLO, 2016). } \\
\text { Não há referência sobre o } \\
\text { Acesso Aberto e não considera } \\
\text { o SciELO ou o Redalyc. }\end{array}$ \\
\hline
\end{tabular}

Fonte: Elaborado pelos autores com base em: Vasen e Lujano Vilchis (2017); tradução nossa.

Segundo Vasen e Lujano Vilchis (2017), os critérios de internacionalização dos periódicos científicos argentinos se distam dos aplicados no México e na Colômbia, porque seus parâmetros, além de normativos, tentam homogeneizar os processos de avaliação acadêmica e o sistema de classificação de periódicos científicos nacionais focados nos termos de qualidade editorial. Já no México, o propósito essencial é hierarquizar os periódicos científicos com a finalidade de estimular seu desenvolvimento, não abordando diretamente a questão da avaliação acadêmica (VASEN, LUJANO VILCHIS, 2017). Quanto à Colômbia, o Publindex considera os critérios de qualidade editorial e um sistema de classificação orientado para a evolução acadêmica (VASEN, LUJANO VILCHIS, 2017). Conforme os autores, México e Colômbia utilizam os indicadores bibliométricos, porém, segundo as Bases para la categorización de publicaciones periódicas en Ciencias Sociales y Humanidades (Resolución 2.249/2014) (ARGENTINA, 2014) a Argentina se mostra contra a inclusão desses parâmetros como forma de estratificar as publicações acadêmicas, reiterando que o fator de impacto não deve ser tomado como critério de qualidade para publicações nas ciências sociais e humanas. 


\section{INTERNACIONALIZAÇÃO DOS PERIÓDICOS CIENTÍFICOS BRASILEIROS}

É necessário ressaltar que atualmente o governo brasileiro não tem um programa nacional explícito o qual norteie e explore claramente a internacionalização do ensino superior, de modo a tratá-la como uma política pública (MIRANDA; STALLIVIERI, 2017, p. 591). Não obstante, e por coincidir com sua missão, esse processo é liderado no Brasil pela Coordenação de Aperfeiçoamento de Pessoal de Nível Superior (CAPES), "fundação ligada ao Ministério da Educação (MEC) que coordena os programas de pós-graduação stricto sensu em todo o país e que vem empreendendo, na última década, ações para a internacionalização da ciência no país" (PEREIRA; LOBAO; LUCAS, 2017, p. 2302). Para essa agência governamental, a internacionalização pode ser entendida enquanto um processo amplo e dinâmico envolvendo ensino, pesquisa e prestação de serviços para a sociedade, além de construir um recurso para tornar a educação superior responsiva aos requisitos e desafios de uma sociedade globalizada (COORDENAÇÃO DE APERFEIÇOAMENTO DE PESSOAL DE NÍVEL SUPERIOR, 2017, p. 6).

Sendo uma das missões da CAPES a promoção da cooperação científica internacional, esta também é sua principal estratégia de internacionalização. Um exemplo é o programa Ciência sem Fronteiras (CsF), que tornou mais visível o processo de internacionalização acadêmica no país (SILVA; DE MARI, 2017, p. 36).

Apesar das realizações da CAPES, o governo brasileiro não tem um delineamento claro sobre a internacionalização dos periódicos científicos nacionais (PEREIRA; LOBAO; LUCAS, 2017, p. 2.309). Inclusive, o Qualis Periódicos, ferramenta para análise e qualificação da produção bibliográfica de docentes e discentes dos programas de pós-graduação credenciados pela CAPES, está isenta de ser usada como referência na internacionalização dos periódicos científicos brasileiros (BARATA, 2016).

De modo geral, a internacionalização dos periódicos científicos no Brasil tem focado bastante na presença dessas publicações nas bases de dados das grandes editoras internacionais, e principalmente das editoras comerciais. Outra prova disso são os editais vinculados ao governo para o fomento de periódicos, os quais têm como função fazer um concurso para que os periódicos científicos de alto impacto sejam selecionados e recebam recursos para a editoração.

Nos editais de fomento ${ }^{9}$ do Conselho Nacional de Desenvolvimento Científico e Tecnológico (CNPq) e da CAPES, um dos destaques que representam a internacionalização está presente no objetivo dos referidos documentos, quando é mencionada a necessidade de o periódico científico ter "alta especialização em todas as áreas do conhecimento" (CONSELHO NACIONAL DE DESENVOLVIMENTO CIENTÍFICO E TECNOLÓGICO, 2016; COORDENAÇÃO DE APERFEIÇOAMENTO DE PESSOAL DE NÍVEL SUPERIOR, 2016, grifo nosso). Então, quanto maior seu aprofundamento temático, maior a chance de receber o fomento, embutindo uma característica da publicação internacional, ou seja, ser um periódico científico especializado. Além disso, há obrigatoriedade de estar nos

9 Nesse período, as agências publicaram três editais; em 2016, ambas publicaram editais separados e, em 2017, desenvolveram um único edital. 
indexadores WoS, Scopus, SciELO, Pubmed e Redalyc (Quadro 3). Os editais têm em comum a intenção de qualificar os periódicos científicos com perfil para internacionalização, com vistas a fazê-los atingir a visibilidade por meio dessas indexações. Para isso, acreditam que a indexação nas referidas bases dará a aceitação da ciência realizada no país. No entanto, conforme a literatura apresentada neste artigo, este é um ponto contraditório, porque, ao se internacionalizar, perde-se o interesse pela agenda local, em função de se adaptar aos interesses globais, ou do país de origem do indexador.

Cabe destacar que ambos os editais de 2016 incluem a necessidade de se ter no mínimo a classificação B2 no estrato Qualis Periódicos; já em 2017, menciona apenas ter algum estrato no Qualis Periódicos. Dependendo da área de conhecimento, quando se cruzam os critérios do Qualis Periódicos com os dos indexadores internacionais, torna-se inviável para um periódico científico que tem como escopo a ciência local concorrer ao fomento.

Quadro 3 - Síntese da presença de internacionalização e de Acesso Aberto nos editais

\begin{tabular}{|c|c|c|c|c|}
\hline Editais & $\begin{array}{l}\text { Internacionalização - } \\
\text { Indexadores }\end{array}$ & $\begin{array}{l}\text { Acesso } \\
\text { Aberto }\end{array}$ & $\begin{array}{c}\text { Corpo } \\
\text { editorial } \\
\text { internacional }\end{array}$ & $\begin{array}{c}\text { Autores } \\
\text { internacionais }\end{array}$ \\
\hline $\begin{array}{l}\text { 1) CNPq } 2016 \\
\text { 2) CAPES } 2016\end{array}$ & $\begin{array}{c}\text { SciELO, ISI (Thompson) Scopus } \\
\text { e Pubmed }\end{array}$ & Sim & Sim & Sim \\
\hline $\begin{array}{l}\text { 3) CNPq e } \\
\text { CAPES } 2017\end{array}$ & $\begin{array}{c}\text { SciELO, WoS }{ }^{10}, \text { Scopus, } \\
\text { Pubmed e Redalyc }\end{array}$ & Sim & \multicolumn{2}{|c|}{$\begin{array}{l}\text { Não cita, apenas inclui a } \\
\text { abrangência da publicação } \\
\text { nacional e internacional }\end{array}$} \\
\hline $\begin{array}{l}\text { UFSM } \\
\text { 4) } 2016 \\
\text { 5) } 2017\end{array}$ & SciELO, WoS e Scopus & $\begin{array}{l}\text { Política } \\
\text { de } \\
\text { acesso }\end{array}$ & Sim & Não \\
\hline $\begin{array}{l}\text { UFPR } \\
\text { 6) } 2016 \\
\text { 7) } 2017\end{array}$ & $\begin{array}{l}\text { 2016: Não menciona; 2017: } \\
\text { 1) WoS, Scopus; 2) SciELO, } \\
\text { Latindex, Redalyc e Lilacs; 3) } \\
\text { Demais bancos/bases de dados }\end{array}$ & Não & Não & Não \\
\hline $\begin{array}{l}\text { UFRGS } \\
\text { 8) } 2016 \\
\text { 9) } 2017\end{array}$ & Não & Não & Sim & Não \\
\hline
\end{tabular}

Fonte: Elaborado pelos autores (2018) com base nos editais.

Muito semelhantes aos editais do CNPq e da CAPES estão os incentivos por parte das universidades, que em sua maioria favorecem os periódicos científicos considerados de alto impacto, internacionais. Por exemplo, entre os anos de 2016 e 2017, das 58 universidades federais brasileiras, apenas três tiveram a oportunidade de lançar editais para o fomento de periódicos, publicando cada uma delas dois editais por ano. As três universidades são: Universidade Federal de Santa Maria (UFSM), Universidade Federal do Paraná (UFPR) Universidade Federal do Rio Grande do Sul (UFRGS).

10 Em 2016, equivocadamente, o edital apresentou o Institute for Scientific Information (ISI) como um indexador, mas, na verdade, ele é um instituto fundado por Eugene Garfield, em 1960, que ajudou a criar a bibliometria e a cientiometria. A Thomsom Reuters comprou o ISI e disponibilizou esses serviços métricos pela Web of Science (WoS). Em 2016, a WoS foi vendida ao grupo Clarivate. 
Os editais da UFSM refletem que o periódico científico deve seguir padrões de qualidade, e evidenciam a necessidade de se seguir os padrões da SciELO, seguidos da WoS e da Scopus, revelando sua estratégia de internacionalizar os periódicos da instituição por meio desses indexadores/editoras (UNIVERSIDADE FEDERAL DE SANTA MARIA, 2016 e 2017 p. 2). Há ausência de outros indexadores dentro dos princípios do Acesso Aberto, por exemplo, o Redalyc. Quanto ao Acesso Aberto, a única menção no edital sugere que os periódicos científicos devem descrever uma política de acesso na candidatura do fomento.

Na UFPR, os editais de 2016 e 2017 são muito distintos um do outro; o primeiro apresenta indicadores de qualidade para melhoria dos periódicos, focados principalmente na padronização de forma e infraestrutura editorial, e não menciona nenhum indicador de internacionalização. Já em 2017, foram considerados outros fatores para distribuir o recurso: bases de indexação, classificação no Qualis Periódicos, número de submissões, índice $\mathrm{H}$ e números de acessos por ano. Com relação às bases para indexação, considera-se a presença preferencial na seguinte sequência: 1) WoS e Scopus; 2) SciELO, Latindex, Redalyc e Lilacs; e 3) podem ser consideradas outras bases (UNIVERSIDADE FEDERAL DO PARANÁ, 2017). Ambos os editais não citam se o investimento é para revistas científicas de Acesso Aberto. As mudanças entre os dois editais evidenciam que, em 2016, havia uma preocupação quanto à manutenção da infraestrutura do periódico, e em 2017, em investir na sua internacionalização, por meio da distribuição/indexação. Um diferencial deste edital foi considerar métricas alternativas, por exemplo, o índice $\mathrm{H}$ (proveniente do Google Metrics) e o número de acessos por ano, ambas acessíveis e gratuitas.

Os dois editais da UFRGS são idênticos, e no que tange à presença da internacionalização, sinalizam a necessidade de se ter abrangência internacional quanto a colaboradores e conselho editorial, assim como estar indexada; entretanto, não indica quais os indexadores e tampouco se o incentivo é para periódicos científicos em Acesso Aberto. De modo geral, os editais da UFRGS são inclusivos porque consideram o status do periódico científico de acordo com o contexto da instituição. Além disso, estão preocupados com as estratégias dos editores sobre como compor equipe editorial internacional.

Apesar de os objetivos dos editais terem em comum a visibilidade da ciência produzida no país, há evidências apontadas em pesquisas (VASEN; LUJANO VILCHIS, 2017; VESSURI; GUÉDON; CETTO, 2015; BIANCO; GRAS; SUTZ, 2016) de que isso é contraditório, por alguns motivos: primeiro, porque não se dará visibilidade à ciência local, tendo em vista que, para ser internacional, é necessário atender à agenda global; segundo, porque o atendimento à agenda global implica, às vezes, o distanciamento dos tópicos locais e, consequentemente, uma menor possibilidade de se ter impacto com as políticas de desenvolvimento local; terceiro, as avaliações das agências de fomento desestimulam as vinculações às agendas locais, em detrimento das internacionais, o que impossibilita a ciência e a tecnologia de cumprirem as promessas de contribuir para o desenvolvimento socioeconômico com as quais procuram justificar o financiamento público.

Quando o governo incentiva com recursos públicos pesquisadores e universidades a terem seus periódicos científicos vinculados a editoras comerciais, pode ser considerado um conflito de interesses: "para que haja essa caracterização, é necessário que esse 
confronto implique prejuízo para o interesse coletivo ou para o desempenho da função pública." (BRASIL, 2013, p. 1). Nesse sentido, Canto esclarece que:

Com base nos princípios da economia livre de mercado não haveria problema algum no fato das editoras perceberem lucros nos índices apontados. Entretanto, quando o assunto é comunicação científica, não está se referindo a um produto ou serviço de consumo qualquer. $\mathrm{O}$ acesso à informação científica disponível em periódicos é indispensável para o desenvolvimento de países, e a privação deste conteúdo àquelas nações que não podem arcar com os custos favorece a desigualdade mundial e a perpetuação do subdesenvolvimento de determinadas regiões. Além disso, mesmo no caso dos países desenvolvidos, parte considerável das pesquisas que dão origem a publicações científicas são financiadas com recursos governamentais. Logo, esse modelo de negócio estaria favorecendo a transferência de recursos públicos para o setor privado. (CANTO, 2018, p. 77)

Esse favorecimento de transferência de recursos tanto monetários quanto científicos acarreta em prejuízos para a sociedade, carecendo de outras pesquisas para o aprofundamento legal dessa relação do governo com as editoras comerciais.

Para a área de administração, por meio da fundamentação na teoria de redes, Borini e Ferreira (2015) acreditam que as instituições que fomentam a internacionalização brasileira também não levam em conta os desafios competitivos intrínsecos ao se inserir a ciência do país de origem no país hospedeiro. A estratégia de camuflar-se em um periódico científico no país hospedeiro usando as mesmas regras desse local não o fará ser aceito pelos pesquisadores daquele país por muito tempo; certamente haverá rejeição (BORINI; FERREIRA, 2015).

\section{RELAÇÃO DA VISIBILIDADE COM A INTERNACIONALIZAÇÃO}

Um aspecto muito recorrente no âmbito das publicações científicas é a correspondência entre a visibilidade de uma publicação e sua internacionalização. Esta é uma relação válida, porém torna-se limitada quando a visibilidade está vinculada à indexação num recurso determinado. Nesse sentido Alperin e Rozemblum (2017) comentam sobre a restrição de uma concepção de visibilidade baseada apenas em ferramentas adaptadas dos países centrais da ciência:

A reinterpretação da visibilidade e impacto por uma medida de citação em bases de dados comerciais também deixa de lado, quiçá o mais importante, o tema da qualidade da ciência regional que foi tão central na etapa de consolidação [...] deveríamos abandonar a interpretação errônea de que a melhor forma de melhorar a pesquisa é juntar-se a um modelo de ciência desenvolvido para um sistema de ciência de outra parte do mundo (ALPERIN; ROZEMBLUM, 2017, p. 237, tradução nossa).

Exemplo disso é a pesquisa de Larivière, Haustein e Mongeon (2015), que estudou por um período de 10 anos os periódicos científicos indexados nas cinco maiores editoras comerciais (Elsevier - Scopus, Clarivate - Thomsom Reuters - Web of Science, 
Wiley-Blackwell, Springer e Taylor \& Francis). Ao acompanharem o número de citações, constataram que, nos primeiros três anos de inserção, houve um pequeno aumento na média de citações, entretanto, este seguiu em queda nos anos seguintes. Isso indica que há pouco ou nenhum aumento no número de citações quando um periódico científico é incluído em uma base de dados internacional; ainda, os autores não mencionaram se os periódicos científicos analisados eram de Acesso aberto.

Na comunidade científica internacional, documentos como o Manifesto de Leiden têm compartilhado certa preocupação devida às limitações geradas pelo uso inadequado das métricas obtidas dos principais sistemas de indexação. Citando o Manifesto de Leiden, Hicks et al. (2015, p. 430) resumiram essas preocupações em 10 princípios, o que foi considerado a melhor prática em avaliação da ciência baseada em métricas, de forma que sirvam de referência aos "pesquisadores [para que] possam exigir dos avaliadores e avaliadores possam exigir dos indicadores que produzem". De forma resumida, estes são os 10 princípios:

1. A avaliação quantitativa deve embasar a avaliação qualitativa, não a substituir.

2. O desempenho deve ser avaliado levando-se em conta os objetivos de pesquisa da instituição, do grupo ou do pesquisador. Não há modelo único de avaliação adequado a todas as circunstâncias.

3. Pesquisa relevante para necessidades locais deve ser protegida. Quando o parâmetro usado é internacional, como os usados pelo Web of Science, a avaliação sofre viés particularmente danoso em áreas como ciências sociais e humanidades, cujos conteúdos estão mais comprometidos com necessidades regionais e nacionais; contudo, isso também afeta outras áreas que apresentam dimensões regionais e nacionais.

4. A coleta de dados deve ser aberta, transparente e simples. Não pode haver caixa preta, secreta. Simplicidade em indicadores é uma virtude porque promove a transparência, entretanto, métricas simplistas podem distorcer a avaliação. Os avaliadores devem se esforçar para conseguir indicadores simples, mas fiéis à complexidade do processo de pesquisa.

5. Deve haver a possibilidade de os pesquisadores avaliados verificarem dados e análises relacionados à sua avaliação. No entanto, a coleta e o processamento de dados precisos e de qualidade exigem tempo e têm custo alto, portanto, é necessário incluir esses gastos no orçamento das instituições.

6. Deve-se levar em conta diferenças nos hábitos de publicação e citação entre as diversas áreas. O melhor é selecionar alguns indicadores e deixar que as diversas áreas escolham aqueles que consideram adequados.

7. A avaliação de indivíduos deve ser baseada em julgamentos qualitativos de seus currículos. A avaliação de um pesquisador baseada na leitura de seus trabalhos é mais apropriada do que aquela baseada em números. Mesmo quando se compara um número grande de pesquisadores, a melhor abordagem é aquela que considera mais informação sobre suas habilidades, atividades, sua experiência e influência.

8. A sensação de precisão e concretude transmitida por indicadores quantitativos deve ser evitada. Indicadores da ciência e da tecnologia tendem a uma ambiguidade conceitual e incertezas que requerem pressupostos fortes e universalmente aceitos. Por exemplo, 
não há consenso sobre o significado da contagem de citações. As melhores práticas incluem o uso de indicadores múltiplos para que se obtenha um quadro mais robusto e pluralista.

9. O próprio processo de avaliação introduz efeitos sistemáticos que devem ser reconhecidos e antecipados. Indicadores podem afetar o sistema por meio dos incentivos que estabelecem. Isso significa que é sempre melhor a adoção de uma combinação de indicadores, pois o uso de um único indicador tende a causar mudança de objetivo, tornando a mensuração o próprio objetivo.

10. Os indicadores adotados devem ser examinados e atualizados regularmente. Objetivos científicos e objetivos de avaliação mudam com frequência. Métricas consideradas úteis em dado momento podem se tornar inadequadas com a emergência de outras métricas.

Ainda, citando Hicks et al. (2015, p. 1),

Cada vez mais se utilizam dados para gerenciar a ciência. As avaliações da pesquisa, que já foram individualizadas, solicitadas e realizadas por pares, atualmente são rotineiras e baseadas em métricas. A questão é que agora a avaliação é majoritariamente dependente de dados, ao invés de juízos de valor. As métricas proliferaram: em geral bem-intencionadas, nem sempre bem informadas, e frequentemente mal aplicadas. Corremos o risco de prejudicar o sistema da ciência com as próprias ferramentas projetadas para melhorá-lo, uma vez que a avaliação é cada vez mais realizada por instituições sem o devido conhecimento sobre as boas práticas e sobre a interpretação adequada de indicadores (HICKS, et al., 2015, tradução nossa).

Nesse sentido, é necessário lembrar que as revistas científicas constituem mais que um veículo da ciência. Sua valoração ser baseada unicamente em parâmetros vinculados à comunicação e métricas deixa de fora outros aspectos importantes, como a sua função social. Para algumas áreas, como as ciências sociais, as métricas científicas não abrangem a totalidade das obras publicadas porque usam principalmente livros para comunicar suas descobertas, meios que não são considerados pelos sistemas de indexação em questão. Segundo Vasen e Lujano Vilchis (2017, p. 203), "o risco de se atribuir um peso preponderante à informação proveniente destes bancos de dados para a avaliação pode levar a desatender resultados de investigação que não se expressam em artigos".

Finalmente, a concepção que tratou de transmitir a nova geração de revistas científicas desenvolvidas na América Latina é de uma ciência própria, com identidade e agenda original de tópicos a desenvolver, a qual coexiste e dialoga com a denominada corrente principal da ciência, e que, principalmente, tem valor e significado para o país onde está sendo financiada a pesquisa. Que a pesquisa venha de fato interferir no fazer da sociedade, que melhore as condições de saúde, econômicas, sociais e políticas, que tenha o apelo para o bem público, e que isso tenha provas para ser medido; uma citação não mede o impacto nesses contextos (BORCHARDT; HARTINGS, 2018). Nas palavras de Alperin e Rozemblum (2017, p. 238), "[...] os primeiros objetivos da região foram fazer visível para o mundo a ciência produzida e editada na América Latina, para que ela se equiparasse com aquela da corrente principal, não para que esta última a absorva". 


\section{OUTRAS LIMITAÇÕES DO PROCESSO DE INTERNACIONALIZAÇÃO}

O contexto analisado evidencia um conjunto de prejuízos gerado pela forma como o processo de internacionalização de periódicos científicos é conduzido tanto para as publicações como para a comunicação científica nos países estudados, incluído o Brasil. Além disso, existem outras limitações que esse tipo de processo pode originar. Por exemplo, Vasen e Lujano Vilchis (2017) consideram que o processo pode marginalizar os periódicos científicos da região na sua perspectiva disciplinar, sobrevalorizando os indicadores bibliométricos e suas fontes e antepondo-os na agenda de trabalho editorial; no âmbito linguístico, afastando as línguas de publicação originais e adotando o inglês como língua franca; na visão geográfica, é discriminado as temáticas de pesquisa local e regional e privilegiando as temáticas da ciência central (Quadro 4).

Quadro 4 - Limitações da internacionalização

\begin{tabular}{|c|c|c|}
\hline Disciplinar & Linguística & Geográfica \\
\hline Sobrevalorização dos & Restrição da cobertura de & Marginalização dos periódicos, \\
indicadores bibliométricos & publicação em espanhol, & com agendas de pesquisa \\
referentes ao impacto das & português e outros idiomas \\
de interesse local e regional. \\
publicações e das bases de \\
dados que fornecem diferentes do \\
inclue \\
informação (Web of Science e \\
Scopus).
\end{tabular}

Fonte: Vasen; Lujano Vilchis (2017); Hicks et al. (2005).

No cenário atual, muitos editores, motivados pela internacionalização de suas publicações, são induzidos a dar preferência aos tópicos de interesse da corrente da ciência central e excluir aqueles de interesse local, circunstância que questionaria o propósito da publicação e do financiamento da pesquisa nesses países.

[...] se encontra fortemente relacionada com o desafio da visibilidade, e o reconhecimento das revistas latino-americanas [...]. As revistas privilegiam a publicação de contribuições que abordam temas atuais ou "na moda" nas disciplinas, os quais costumam estar unidos às tendências predominantes nos países que as editam. O problema surge porque, como temos visto, a grande maioria das revistas que figuram nas principais bases de dados bibliométricas são editadas em países centrais que têm mais preferência pelos temas que se estão discutindo lá. [...]. As ciências sociais constituem um espaço marginalizado pelos principais indicadores bibliométricos. (VASEN; LUJANO VILCHIS, 2017, p. 204-205).

Outra preocupação é com as áreas predominantes na América Latina, como as Ciências Sociais e as Humanidades, cujas dinâmicas de pesquisa nem sempre se adequam às exigências de produção dos índices internacionais, enfrentando, desse modo, dificuldades para serem indexadas, ficando exiladas e prejudicando sua própria avaliação 
pelos órgãos de controle (QUISPE-GERÓNIMO, 2015), criando uma tensão e pressão no ambiente acadêmico não apenas na área das Humanidades, mas em todas as áreas (BORINI, FERREIRA, 2015).

\section{CONCLUSÕES}

Corroboramos que não existe um delineamento explícito sobre a internacionalização dos periódicos científicos de parte dos organismos governamentais brasileiros, circunstância que afeta negativamente essas publicações. Os critérios aplicados pelas agências nacionais de fomento para outorgar verbas de apoio à editoração dos periódicos científicos não contemplam a diversidade e variedade deles. Essa circunstância, além de excluir muitas dessas publicações, limita o desenvolvimento de todas aquelas que ficam fora dos parâmetros estabelecidos.

Nesse cenário, consideramos que é necessário propiciar o diálogo entre os diferentes atores envolvidos, tanto no âmbito da editoração científica brasileira como no processo de internacionalização dos periódicos científicos, para alcançar uma conjuntura inclusiva. Assim, corresponderia, por um lado, às editoras, na maioria dos casos universidades (federais e estaduais), negociar com as agências nacionais, na busca de melhores oportunidades de apoio para suas publicações. Por outro, aos editores científicos, corresponderia assumir uma atitude proativa, adotando as ações estratégicas necessárias para se articular ao processo de internacionalização, no entanto, mantendo a essência de cada projeto editorial: seu escopo, seu objetivo e sobretudo sua qualidade integral.

Mesmo que em outros países da região o processo de internacionalização dos periódicos científicos se dá em circunstâncias similares, como se vem dando atualmente no caso brasileiro, existem outros fatores que podem oportunizar melhores condições no processo de publicações locais. Por exemplo, o Brasil, além de ser o país com o maior número de periódicos científicos da região, é o único que tem uma representação formal por meio da associação de editores científicos. Outrossim, existem alternativas na esfera das agências nacionais de apoio à ciência, como as Fundações Estaduais de Amparo à Pesquisa (FAPs), que podem contribuir de maneira estratégica com o processo de internacionalização dessas publicações.

Acreditamos que a internacionalização da ciência desenvolvida nos países da América Latina, como o Brasil, deve ser um projeto coletivo, em que se reflitam nossos interesses sociais e se proponham respostas a nossas necessidades de desenvolvimento integral. Nesse sentido, no processo de internacionalização dos periódicos científicos latino-americanos, deve-se prevalecer o princípio da informação científica como bem público, e em consequência, todas as ações necessárias para garantir o livre acesso à produção científica a qualquer cidadão.

Quanto às questões sobre a avaliação da produção científica relacionada à pressão dos periódicos científicos serem de alto impacto/internacionalizados, sugerimos que as agências de fomento adotem outros modelos de nações (Finlândia, Países Baixos, Portugal, 
Alemanha, Canadá, Reino Unido, Estados Unidos, Polônia, Índia, Bélgica, China, Coreia, França, Holanda, Japão, Noruega e Áustria ) (URIBE-TIRADO; OCHOA, 2018), que estão seguindo um caminho diferente dessa internacionalização que foi discutida no presente artigo. Com fundamentos na Ciência Aberta, esses países propõem um novo olhar para analisar o impacto real do desenvolvimento científico, levando em conta as necessidades e a avaliação da própria sociedade. Entendemos como impacto real aquilo de que a sociedade se beneficia diretamente, sendo capaz de reconhecer seu investimento e que foi bem aplicado, recebendo ela própria as vantagens oriundas das pesquisas científicas.

Exemplo de aplicação da ciência aberta ocorreu no Reino Unido, que criou o Sistema de Excelência em Pesquisa (Research Excellence Framework - REF) como solução para confirmar o impacto real da pesquisa, medido diretamente com os beneficiários ${ }^{11}$ da pesquisa. Isso significa que as pessoas fora das universidades serão ouvidas, ou seja, a sociedade em geral. Esse resultado ajudará os gestores a avaliar melhor o impacto real na sociedade, e não apenas o do uso da literatura do que é produzido, isso com referência ao fator de impacto das publicações (GUNN; MINTROM, 2017). Para esses autores (2017, p. 1), a avaliação de impacto deve levar em conta os fatores "não econômicos, tais como: qualidade de vida, mudança ambiental e saúde pública. Mesmo que seja difícil colocar valores monetários nessas coisas."

Ao contrário do Reino Unido, alguns países da América Latina estão importando um modelo tradicional de fomento de pesquisa e de publicação periódica, baseado principalmente no fator de impacto, na sua aderência internacional por meio das maiores editoras do mundo. Consideramos que esse modelo tradicional é insustentável, sendo a transição para a Ciência Aberta a solução mais indicada, sinônimo de transparência, colaboração, acessibilidade, contribuindo com o impacto real, e não apenas documental, na sociedade.

\section{REFERÊNCIAS}

ALBORNOZ, Mario (Coord). Manual de indicadores de internacionalización de la ciencia y la tecnología: Manual de Santiago 2007. Buenos Aires: Red de Indicadores de Ciencia y Tecnología Ibero/Interamericanos - RICyT, 2009. 130 p. Disponível em: < http:// www.ricyt.org/manuales/doc_download/1-manual-de-santiago > . Acesso em: 30 jun. 2018.

ALPERIN, Juan Pablo; ROZEMBLUM, Cecilia. La reinterpretación de visibilidad y calidad en las nuevas políticas de evaluación de revistas científicas. Revista Interamericana de Bibliotecología, [s.I.], v. 40, n. 3, p. 231-241, sep. 2017. Disponível em: <https://aprendeenlinea.udea.edu.co/revistas/index.php/RIB/article/ view/327794/20785493>. Acesso em: 30 jun. 2018.

11 Com exceção para alguns trabalhos que não podem ser investigados com as pessoas envolvidas, como no caso de alguns temas da medicina. 
julho/2018

ANGLADA, Luís; ABADAL, Ernest. ¿Qué es la ciencia abierta? Anuario Thinkepi, [s.I.], v. 12, p.292-298, 2018. Ediciones Profesionales de la Informacion SL. Disponível em: < https:// recyt.fecyt.es/index.php/ThinkEPI/article/download/thinkepi.2018.43/39164>. Acesso em: 04 jun. 2018.

AGUDELO TRUJILLO, Jorge H. El extraño viraje del PUBLINDEX. Ver. Colom. Cienc. Pecua, Medellín, v. 29, n. 4, p. 243-244, dez. 2016. Disponível em: < http://www. scielo.org.co/scielo.php?script = sci_arttext\&pid =S0120-06902016000400243\&lng = en\&nrm = iso > . Acesso em: 30 jun. 2018.

ARGENTINA. Directorio del Consejo Nacional de Investigaciones Científicas y Técnicas.

Resolución 2249 del 25 de Junio de 2014. Bases para la Categorización de Publicaciones Periódicas en Ciencias Sociales y Humanidades. Disponível em: < http://www.conicet. gov.ar/bases-para-la-categorizacion-de-publicaciones-periodicas-en-cienciassociales-y-humanidades/>. Acesso em: 30 jun. 2018.

BARATA, R. de C. B. Dez coisas que você deveria saber sobre o Qualis. Revista Brasileira da Pós-Graduação, Brasília, v. 13, n. 30, p. 13-40, jan./abr. 2016. DOI: http://dx.doi. org/10.21713/2358-2332.2016.v13.947

BIANCO, Mariela; GRAS, Natalia; SUTZ, Judith. Academic Evaluation: Universal Instrument? Tool for Development? Minerva, v. 54, n. 4, p. 399-421, 2016. Disponível em: < https://link.springer.com/article/10.1007/s11024-016-9306-9 > Acesso em: 30 maio 2018.

BORCHARDT, Rachel; HARTINGS, Matthew R. The academic papers researchers regard as significant are not those that are highly cited. 2018. Disponível em: < http://blogs. Ise.ac.uk/impactofsocialsciences/2018/05/14/the-academic-papers-researchersregard-as-significant-are-not-those-that-are-highly-cited/ > . Acesso em: 30 maio 2018.

BORINI, F. M.; FERREIRA, J. Internacionalização de Periódicos Científicos Brasileiros: Estudo de Caso à luz da Teoria de Redes e da Teoria Institucional. Revista IberoAmericana de Estratégia, v. 14, n. 4, p. 24-40, 2015. Disponível em: < http://www. revistaiberoamericana.org/ojs/index.php/ibero/article/view/2252 > Acesso em: 30 maio 2018.

BRASIL. Lei no 9.986, de 1 de julho de 2013. Dispõe sobre o conflito de interesses no exercício de cargo ou emprego do Poder Executivo federal e impedimentos posteriores ao exercício do cargo ou emprego; e revoga dispositivos da Lei no 9.986, de 18 de julho de 2000, e das Medidas Provisórias nos 2.216-37, de 31 de agosto de 2001, e 2.225-45, de 4 de setembro de 2001. Brasília, Disponível em: < http://www.planalto. gov.br/ccivil_03/_Ato2011-2014/2013/Lei/L12813.htm >. Acesso em: 10 maio 2018.

CANTO, Fábio Lorensi do. Análise de citação de teses: uma abordagem por área do conhecimento. Dissertação (mestrado) - Universidade Federal de Santa Catarina, Centro de Educação, Programa Pós-Graduação em Ciência da Informação, Florianópolis, 2018. Disponível em: < https://repositorio.ufsc.br/handle/123456789/186803 > . Acesso em: 20 maio 2018. 
COORDENAÇÃO DE APERFEIÇOAMENTO DE PESSOAL DE NÍVEL SUPERIOR. A internacionalização na Universidade Brasileira: resultados do questionário aplicado pela CAPES. Brasília, 2017. Disponível em: < http://www.capes.gov.br/images/ stories/download/diversos/A-internacionalizacao-nas-IES-brasileiras.pdf > Acesso em: 05 jun. 2018.

COORDENAÇÃO DE APERFEIÇOAMENTO DE PESSOAL DE NÍVEL SUPERIOR. Edital para apoio financeiro à editoração e publicação de periódicos científicos brasileiros: Edital N 13/2016. Ofício nº 001-98/DAD. Brasília, 2016. Disponível em: < https:// www.capes.gov.br/images/stories/download/editais/01052015-Edital-13Editoracao-2016.pdf > . Acesso em: 30 maio 2018.

CONSELHO NACIONAL DE DESENVOLVIMENTO CIENTÍFICO E TECNOLÓGICO. Chamada MCTIC/CNPq No 25/2016. Brasília: [s n.], 2016. Disponível em: < http:// cnpq.br/chamadas-publicas?p_p_id=resultadosportlet_WAR_resultadoscnpqportlet_ INSTANCE_OZaM\&filtro=abertas\&detalha=chamadaDivulgada\&idDivulgacao=6903 > Acesso em: 05 jun. 2018.

CETTO KRAMIS, Ana María; ALONSO GAMBOA, José Octavio (Comp.). Calidad e Impacto de la revista Iberoamericana. México: UNAM, 2011.

ESTADOS UNIDOS. National Science Board. National Center for Science and Engineering Statistics - NCSES. Science and Engineering Indicators 2016 (NSB-2016-1). Alexandria (Virginia): NSB. 2016. Disponível em: < https://www.nsf.gov/statistics/2016/ nsb20161>. Acesso em: 21 jan. 2018.

GUNN, Andrew; MINTROM, Michael. Five things to consider when designing a policy to measure research impact. 2017. Disponível em: < https://theconversation.com/ five-things-to-consider-when-designing-a-policy-to-measure-research-impact-71078> . Acesso em: 04 jun. 2018.

GUNN, André; MINTROM, Michael. Medindo o impacto da pesquisa na Austrália. Revista das Universidades Australianas, v. 60, n. 1, p. 9, 2018. Disponível em:<http://linkgalegroup.ez46.periodicos.capes.gov.br/apps/doc/A534879033/AONE?u = capes\&sid $=$ AONE \&xid $=$ cc20cd31 > . Acesso em 5 de jun. 2018.

HICKS, D. et al. Bibliometrics: The Leiden Manifesto for research metrics. Nature, v. 520, n. 7548, p. 429-431, 2015. Disponível em:<https://www.nature.com/news/ bibliometrics-the-leiden-manifesto-for-research-metrics-1.17351>. Acesso em: 20 jan. 2018.

KNIGHT, J. Internationalization Remodeled: Definitions, Rationales, and Approaches. Journal for Studies in International Education, v. 8, n. 1, p. 5-31, 2004. Disponível em: <https://doi.org/10.1177/1028315303260832>. Acesso em: 20 jan. 2018.

LARIVIÈRE, V.; HAUSTEIN, S.; MONGEON, P. The Oligopoly of academic publishers in the digital era. PLoS ONE, v. 10, n. 6, p. 1-15. e0127502. DOI: Disponível em: < http:// dx.doi.org/10.1371/journal.pone.0127502 >. Acesso em: 20 jan. 2018.

MIRANDA, José Alberto Antunes de; STALLIVIERI, Luciane. Para uma política pública de internacionalização para o ensino superior no Brasil. Avaliação (Campinas), Sorocaba , v. 22, n. 3, p. 589-613, dez. 2017. DOI: http://dx.doi.org/10.1590/ s1414-40772017000300002 
julho/2018

PACKER, Abel L. et. al. (Org.). SciELO - 15 Anos de Acesso Aberto: um estudo analítico sobre Acesso Aberto e comunicação científica. Paris: UNESCO, 2014. Disponível em: <http://www.scielo.org/local/File/livro.pdf > . Acesso em: 30 maio 2018.

PEREIRA, D. B.; LOBAO, I. S. L.; LUCAS, E. R. O. Internacionalização de periódicos científicos brasileiros: exigências requeridas. Revista Brasileira de Biblioteconomia e Documentação, v. 13, 2017. Disponível em: < http://www.brapci.inf.br/v/a/28406 > . Acesso em: 06 jun. 2018.

QUISPE-GERÓNIMO, Carlos. El manifiesto de Leiden: aclarando el panorama sobre la evaluación de la investigación. Lima, 2015. Disponível em: <http://carlosqg.info/ index.php/articulos/212-manifiesto-leiden >. Acesso em: 25 jan. 2018.

SCIENTIFIC ELECTRONIC LIBRARY - SCIELO. São Paulo, 2018. Disponível em: < h http:// www.scielo.org > . Acesso em: 21 jan. 2018.

SILVA, Wanessa de Assis; DE MARI, Cezar Luiz. Internacionalização e ensino superior: história e tendências atuais. Revista de Políticas Públicas e Segurança Social, [S.I.], v. 1, n. 1, p. 36-53, set. 2017. ISSN 2594-3855. Disponível em: < https://www. nepppss.com/revista/index.php/revistappss/article/view/2017010102 > . Acesso em: 30 jun. 2018.

SILVEIRA, Lúcia da. Portais de periódicos das universidades federais brasileiras: documentos de gestão. 2016. 195 f. Dissertação (Mestrado) - Programa de Pós-Graduação em Gestão da Informação, Universidade do Estado de Santa Catarina, Florianópolis, 2016.

UNIÃO EUROPEIA. Third European Report on Science \& Technology Indicators 2003: Towards a knowledge-based economy. Luxembourg: Office for Official Publications of the European Communities, 2003. Disponível em: < http://cordis.europa.eu/pub/ indicators/docs/3rd_report.pdf > . Acesso em: 25 jan. 2018.

UNIVERSIDADE FEDERAL DO PARANÁ. Edital de apoio à editoração e publicação de periódicos científicos: 2016. Pró-Reitoria de Pesquisa e Pós-Graduação. Disponível em: <http://www.prppg.ufpr.br/sites/default/files/documentos/mestrado_ doutorado/periodicos/Edital_2016_Apoio_Periodicos.pdf $>$. Acesso em: 30 maio 2018.

UNIVERSIDADE FEDERAL DO PARANÁ. Edital de apoio à editoração e publicação de periódicos científicos: 2017. Pró-Reitoria de Pesquisa e Pós-Graduação. Disponível em: < http://www.prppg.ufpr.br/site/wp-content/uploads/2017/07/edital_2017_ apoio-aos-peridicos.pdf $>$. Acesso em: 30 maio 2018.

UNIVERSIDADE FEDERAL DO RIO GRANDE DO SUL. Programa de Apoio à Edição de Periódicos Científicos da UFRGS: Edital 2016. Pró-Reitoria de Pesquisa. Rio Grande do

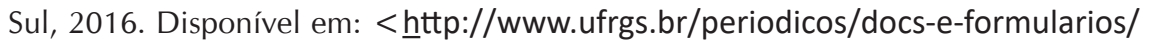
edital-2016> Acesso em: 30 maio 2018.

UNIVERSIDADE FEDERAL DO RIO GRANDE DO SUL. Programa de Apoio à Edição de Periódicos Científicos da UFRGS: Edital 2017. Pró-Reitoria de Pesquisa. Rio Grande do Sul, 2017. Disponível em: < http://www.ufrgs.br/periodicos/docs-e-formularios/ paep/edital-2017> Acesso em: 30 maio 2018. 
UNIVERSIDADE FEDERAL DE SANTA MARIA. Edital $\mathbf{n}^{\circ}$ 027/PRPGP/UFSM, DE 07 DE JUNHO DE 2016: Programa Especial de Incentivo às Revistas Científicas "Pró-Revistas". Pró-reitoria de Pós-graduação e Pesquisa. Rio Grande do Sul, 2016. Disponível em: < http://prpgp.ufsm.br/images/editais-internos/2016/EDITAL_N\%C2\%BA_027_ PRPGP_UFSM_DE_07_DE_JUNHO_DE_2016.pdf $>$ Acesso em: 30 maio 2018.

UNIVERSIDADE FEDERAL DE SANTA MARIA. Edital $\mathbf{n}^{\circ}$ 019/PRPGP/UFSM, DE 19 DE

MAIO DE 2017: Programa Especial de Incentivo às Revistas Científicas "Pró-Revistas". Pró-reitoria de Pós-graduação e Pesquisa. Rio Grande do Sul, 2017. Disponível em: < http://prpgp.ufsm.br/images/editais-internos/2017/pr\%C3\%B3_revistas/ EDITAL_019_PRPGP_UFSM_PRO-_REVISTAS_2017.pdf > Acesso em: 30 maio 2018.

URIBE-TIRADO, Alejandro; OCHOA, Jaider. Perspectivas de la ciencia abierta: un estado de la cuestión para una política nacional en Colombia. BiD: textos universitaris de biblioteconomia i documentació, n. 40, jun. 2018. Disponível em: < http://bid.ub.edu/ es/40/uribe.htm >. Acesso em: 15 jun. 2018.

URIBE-TIRADO, Alejandro El Acceso Abierto en Colombia. Un camino por recorrer.... Cuadernos Fronterizos, n. 38, 2016. Disponível em: < http://eprints.rclis.org/30522/>. Acesso em: 25 jan. 2018.

VASEN, Federico; LUJANO VILCHIS, Ivonne. Sistemas nacionales de clasificación de revistas científicas en América Latina: tendencias recientes e implicaciones para la evaluación académica en ciencias sociales. Revista Mexicana de Ciencias Políticas y Sociales, [S.I.], v. 62, n. 231, ago. 2017. Disponível em: < http://www.revistas.unam. mx/index.php/rmcpys/article/view/58652 > . Acesso em: 25 jan. 2018.

VESSURI, Hebe; GUÉDON, Jean-Claude; CETTO, Ana María. Excellence or Quality? Impact of the Current Competition Regime on Science and Scientific Publishing in Latin America and its Implications for Development. Current Sociology, 2014, v. 62, n. 5, p. 647-665. Disponível em: < http://journals.sagepub.com/doi/ abs/10.1177/0011392113512839>. Acesso em: 25 jan. 2018. 